\title{
Escolares migrantes y profesorado: reflejos de la opresión en la escuela chilena actual
}

\author{
María Loreto Mora-Olate, Ph.D. ${ }^{a}$ \\ Universidad Autónoma de Chile, Chile
}

maria.mora@uautonoma.cl

\section{Resumen (analítico)}

El artículo, derivado de una investigación cualitativa, analiza críticamente la tesis referida a la condición de opresión compartida entre los docentes y alumnado migrante que está arribando sostenidamente a la escuela chilena. Ambos actores oprimidos, en el sentido freiriano, son analizados en el espacio escolar a través de una revisión documental, retomando conceptos claves de la teoría de la reproducción de Bourdieu y Passeron y de los planteamientos de Althusser, que significan la escuela en su función ideológica y represora. La condición de opresión prevalece a las diferencias culturales, siendo los docentes también migrantes en la escuela tensionada por la diversidad cultural. Se concluye que un primer paso para la liberación radica en la toma de conciencia de dicha circunstancia, emergiendo como esperanza liberadora la construcción de una pedagogía crítica latinoamericana.

\section{Palabras clave}

Migrante, docente, escuela, opresión.

\section{Thesauro}

Tesauro de Ciencias Sociales de la Unesco.

\section{Para citar este artículo}

Mora-Olate, M. L. (2021). Escolares migrantes y profesorado: reflejos de la opresión en la escuela chilena actual. Revista Latinoamericana de Ciencias Sociales, Niñez y Juventud, 19(2), 1-20.

https://dx.doi.org/10.11600/rlcsnj.19.2.4345

\section{Historial}

Recibido: 01.05.2020

Aceptado: 03.1.2020

Publicado: 30.04 .2021

\section{Información artículo}

Este artículo se deriva del trabajo de investigación de tesis doctoral Currículum y diversidad cultural: un estudio desde disciplinas escolares y discursos docentes en establecimientos educacionales con alumnado de origen migrante, desarrollado entre octubre de 2015 y septiembre de 2019 (Programa de Doctorado en Educación en Consorcio. Universidad del Bío-Bío, Chillán, Chile). La investigación ha sido financiada por la Comisión Nacional de Investigación Científica y Tecnológica, a través del Programa de Formación de Capital Humano Avanzado, Beca Doctorado Nacional n. 21170381 (2017). Área: ciencias de la educación. Subárea: educación general. 


\section{Migrant students and teachers: reflections on oppression in Chilean schools}

\section{Abstract (analytical)}

This paper is based on qualitative research and critically analyzes the thesis referring to the condition of shared oppression between teachers and migrant students who are steadily enrolling in Chilean schools. In the Freirean sense, both oppressed actors are analyzed in the school space through a literature review that refers to key concepts of Bourdieu and Passeron's theory of reproduction and Althusser's statements, which view the school in its ideological and repressive function. The condition of oppression prevails to cultural differences, with both teachers and migrant students in the school being stressed by cultural diversity. It is concluded that a first step for liberation lies in awareness of this circumstance, which emerges as a liberating hope the construction of a critical Latin American Pedagogy.

Keywords

Migrant, teacher, school, oppression.

\section{Alunos e professores migrantes: reflexões de opressão na atual escola chilena}

\section{Resumo (analítico)}

O artigo, derivado de pesquisa qualitativa, analisa criticamente a tese referente à condição de opressão compartilhada entre professores e estudantes migrantes que chegam constantemente à escola chilena. Ambos atores oprimidos, no sentido freiriano, são analisados no espaço escolar, através de uma revisão documental, retomando conceitos-chave da teoria da reprodução das abordagens de Bourdieu e Passeron e Althusser, o que significa a escola em sua função ideológica e repressiva. A condição de opressão prevalece às diferenças culturais, os professores também são migrantes na escola tensionada pela diversidade cultural. Conclui-se que um primeiro passo para a libertação reside na consciência desta circunstância, emergindo como uma esperança libertadora a construção de uma pedagogia crítica latino-americana.

Palavras-chave

Migrantes, professor, escola, opressão.

Información autora

[a] Doctora en Educación.Chile. Grupo de Investigación Literatura y Escuela (LyE). Universidad Autónoma de Chile, Chile. (ID) 0000-0002-7631-9179. H5: 2. Correo electrónico. maria.mora@uautonoma.cl 


\section{Introducción}

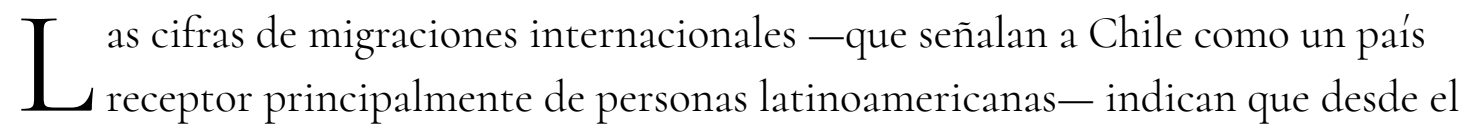
regreso de la democracia en el año 1990 hasta hoy la migración latinoamericana ha cuadruplicado. Es así como entre el año 2005 y el 2017 la llegada de inmigrantes a Chile se incrementó en un $400 \%$ (Segovia \& Rendón, 2020). De acuerdo con datos provenientes de la encuesta Casen, sistematizados por Fuentes y Hernando (2019), en el año 2006 se registraban 154642 inmigrantes en Chile ascendiendo a 777407 en 2017. Porcentualmente, el Censo del 2017 registra un 4.7 por ciento de población inmigrante y un estudio del INE y del DEM proyectó 1252225 para fines del 2018.

Para las personas migrantes el acceso al sistema escolar constituye un importante espacio de socialización y de mecanismo de incorporación al país de acogida. Es así como la matrícula de estudiantes extranjeros a nivel nacional ha experimentado un aumento considerable: en 2014 se encontraban matriculados 22425 estudiantes extranjeros; en 2015, un total de 30 625, duplicándose la cifra en 2016 con 61086 y llegando en 2017 a 77608 (Ministerio de Educación de Chile, 2018). Este aumento de la matrícula se observa especialmente en el sector municipalizado, gratuito, con alto índice de vulnerabilidad y con resultados Simce por debajo del promedio nacional (Eyzaguirre et al., 2019). Es así que el $57 \%$ de los estudiantes extranjeros están matriculados, aumentado su tasa de $1.5 \%$ el año 2015 al 3.5\% el 2017 y a un 5.3\% en el año 2018. De tal forma, la «población escolar inmigrante aumentó en $47 \%$ con 114407 estudiantes matriculados en establecimientos escolares con reconocimiento oficial del Estado» (Eyzaguirre et al., 2019, p. 156). Este significativo aumento ha contribuido a la estabilización de la matrícula municipal, pero, a su vez, ha creado la necesidad de observar y analizar con mayor profundidad el nuevo contexto de estas comunidades educativas (Ministerio de Educación de Chile, 2018). La guetización del alumnado migrante en escuelas municipales (Tijoux, 2013) no es observable en las regiones del centro sur del país, donde la migración es aún un fenómeno emergente, 
pero sí se observa en escuelas y liceos de dicha dependencia administrativa ubicados en la región Metropolitana de Santiago.

La mayor presencia de estudiantado extranjero ha venido también a relevar un rasgo de la escuela — su diversidad - ya sea esta derivada de aspectos de tipo geográfico, etario, género, étnico y cultural; todos factores que ponen en conflicto la función normalizadora y de asimilación que ejerce específicamente en el caso de la niñez y juventud migrante. Al respecto, y paradójicamente, se espera que la escuela actúe como agente relevante en la promoción del respeto por el otro y en la generación de acciones de integración que incluyan a todos los miembros de la comunidad educativa; en especial, el profesorado, cuya formación inicial aún no ha incorporado directamente la escolarización de dicho grupo.

En este contexto, y a través de un análisis documental, la tesis que se desarrolla en este ejercicio reflexivo estima que tanto el profesorado y los niños, niñas y jóvenes que arriban a nuestro país, producto de los proyectos migratorios de sus padres, son reflejo de la opresión cultural que la escuela ejerce sobre ellos.

La problemática apunta a que, como consecuencia del perfil formativo predominante en las facultades de educación, el profesorado adolece de competencias profesionales que le permitan participar en la política pública, ya sea en su diseño o transposición didáctica reflexiva y contextualizada en el aula; así, asumen solo un rol técnico de implementación, sin cuestionar lo que otros han pensado por él. En el caso de los niños, niñas y jóvenes migrantes que tienen asegurado el acceso al sistema escolar, pero no así las condiciones sociales e identitarias al interior de la escuela, sufren racismo y deslegitimación de sus saberes.

En esta argumentación, escolares migrantes y docentes, en su condición freiriana de oprimidos, son analizados desde el espacio escolar institucionalizado y opresor, para lo cual se retoman conceptos claves de la teoría de la reproducción de Bourdieu y Passeron (1996) y de los planteamientos de Althusser (1987) que significan a la escuela en su función ideológica y represora, aspectos abordados en el aparto número tres del artículo. En la tercera parte, el abordaje de la escuela chilena se vincula con la categoría de diversidad cultural. En el cuarto acápite se analiza la condición de oprimidos de ambos actores sociales, escolares migrantes y docentes. Al finalizar, en la quinta parte, la reflexión intenta bosquejar una propuesta liberadora de la opresión, pasando del reflejo a la refracción, desde una concepción dialógica, de igualdad de diferencias, antecedente de la construcción de una pedagogía crítica latinoamericana, implicando un giro tanto en el rol del docente como en su relación pedagógica con el escolar migrante. 


\section{Método}

«El análisis documental considera un conjunto de materiales en formato escrito o audiovisual» (Albert, 2007, p. 252), los cuales «se someten a una examinación sistemática y planificada» (Sabariego et al., 2012, p. 349) y, en este caso, desde una perspectiva crítica. Se consideran documentos escritos de teóricos de la teoría de la reproducción y de la pedagogía crítica, así como también documentación del Ministerio de Educación de Chile y estudios empíricos vinculado a la materia de interés, recuperados a través de bases de datos como Web of Science.

\section{Desarrollo/análisis}

\section{La escuela como aparato ideológico del Estado y campo de la reproducción}

La escuela es una institución especializada que ejerce una acción pedagógica intencional y organizada llevada a cabo por agentes especializados. A diferencia de otras instituciones donde se llevan a cabo aprendizajes, aquí la acción pedagógica constituye el objetivo principal de la institución (Martín-Criado, 2010).

Esta estrategia tuvo éxito, ya que introdujo la hipótesis pedagógica en el corazón del pensamiento básico del Estado-nación situando a la escuela en el centro de sus repertorios de acción política. No en vano Althusser (1987) denomina a la escuela como aparato ideológico del Estado, afirmando que desempeña la función dominante entre los restantes aparatos ideológicos del Estado (el religioso, familiar, jurídico, político, sindical, de la información y cultural). Entonces, la escuela se constituiría en un aparato represor de la diversidad cultural, donde «la enajenación cultural excluye la conciencia de la enajenación. Porque la dominación fundada en el capital cultural es mucho más estable, mucho más fuerte que una dominación fundada solamente en el capital económico» (Bourdieu, 2003, p. 173).

La burguesía reemplaza a la Iglesia por el aparato escolar, constituyéndose en el «real aparato ideológico del Estado dominante en la sociedad capitalista» (Althuser, 1987, p. 41), escenario que reproduce las relaciones de explotadores a explotados, a través de mecanismos disimulados que ubica a la escuela como un medio neutro, carente de ideología alguna (Althuser, 1987, p. 45). 
Complementando lo anterior, la escuela entendida desde Bourdieu y Passeron (1996) como campo de la reproducción de la cultura dominante, «contribuye así a reproducir la estructura de las relaciones de fuerza, en una formación social en que el sistema de enseñanza dominante tiende a reservarse el monopolio de la violencia simbólica legítima» (p. 46). Desde este marco, proponemos la tesis referida a la situación de opresión y de migrancia compartida tanto por los escolares migrantes y los docentes, porque a través de la comunicación pedagógica, de inculcación y de imposición cultural, ambos son despojados de los saberes que portan. El docente, desde su formación inicial y exigencias de desempeño, está constreñido al campo del aula en particular y no al de la escuela, en general, donde los saberes legítimos corresponden a la cultura dominante, bajo un paradigma curricular por competencias. Por su parte, el escolar migrante, como efecto del trabajo pedagógico, debe interiorizar un habitus; es decir, «el grado de realización cultural, grado de competencia legítima, en el que un grupo o una clase reconoce al hombre plenamente realizado» (Bourdieu \& Passeron, 1996, p. 75), donde sus saberes propios y formas de conocer son silenciados en el currículo escolar, de corte etnocentrista, que los considera como pertenecientes a culturas inferiores.

\section{Escuela chilena y diversidad cultural: una historia de desencuentros}

Una breve mirada diacrónica al desarrollo de la institución escolar en Chile demuestra una relación de tensión permanente con la diversidad cultural. Un primer signo de la relación conflictiva de esta institución se relaciona con los saberes que portan los sujetos de las culturas originarias predominante orales, «en el sentido que la forma de comunicación era la palabra hablada y el signo no tenía representación fonética, no era un sonido» (Serrano et al., 2013, p. 26). Ellos se enfrentan a la cultura letrada impuesta por la escuela, portadora del saber superior y legítimo; por tanto, las culturas nativas eran consideradas bárbaras e ignorantes y que debían ser convertidas al catolicismo.

Tal como ocurre en otros países, ${ }^{1}$ los niños, niñas y jóvenes migrantes que llegan a Chile en su gran mayoría se escolarizan en establecimientos educacionales municipalizados, debido a su situación económica precaria, revelando un acceso segregado (Stefoni et al., 2010). La escuela chilena en la actualidad cuenta con una creciente migración latinoame-

\footnotetext{
${ }^{1}$ Cabe señalar que existe una abundante literatura en el campo de educación escolar de los niños y niñas migrantes tanto en Estados Unidos como en México, la cual no se revisa en este trabajo para centrar la atención en el caso chileno.
} 
ricana, con hijos e hijas de migrantes que arriban al sistema escolar municipalizado representativo de la cultura hegemónica occidental, con un rol atribuido de reproducción de conocimiento, desde la matriz colonial y como aparato de control ideológico del Estado (Althusser, 1987). Allí los docentes contribuyen a que los saberes culturales que porta dicho alumnado extranjero sean predominantemente desplazados, bajo el imperativo de adaptación a un determinado saber, concentrado en el currículo escolar y que es vehiculado a través de los discursos docentes, bajo un carácter colonial que rige la acción educativa (Quintriqueo et al., 2014).

Por lo tanto, los y las estudiantes migrantes llegan a un espacio escolar de imposición cultural, donde confluyen la diversidad étnica y cultural, enfrentando una serie de dificultades tanto a nivel idiomático-lingüístico, como a nivel cultural. Entre estas, una de las más complejas es la situación de discriminación o racismo, la cual afecta el proceso de escolarización, especialmente cuando dicha discriminación está presente en las actitudes y discurso de los docentes, constituyéndose en una violencia simbólica (Bourdieu \& Passeron, 1996). Esta es denominada por Jiménez (2012) violencia institucional-simbólica, que se refleja, consecuentemente, en sus prácticas pedagógicas (Riedemann \& Stefoni, 2015; Tijoux, 2013).

En la escuela el racismo no ha sido trabajado en profundidad y se le menciona usando otras categorías menos duras como discriminación, estereotipo o prejuicio (Tijoux, 2013). La mayor parte de los miembros de la escuela tiende a negar a través de diversos mecanismos la existencia de racismo (Riedemann \& Stefoni, 2015), produciéndose una legitimación por parte de los docentes de dichas prácticas (bromas y acusaciones por parte de los alumnos chilenos). Además niños y niñas de familias inmigradas «se ven expuestos a una discontinuidad entre los valores y las prácticas de su familia, que son de orientación colectivista, y los de la sociedad de destino, de tipo individualista» (Henao-Agudelo et al., 2016, p. 605).

La diversidad cultural tensiona a la escuela, a los profesores y a los estudiantes, porque la diversidad es vista más como «una debilidad del sistema que una riqueza conducente» (Orellana, 2009, p. 51). Entonces, la escuela no cumpliría un rol de acogida, sino más bien es un sistema estratificador y segmentador. A juicio de Santos-Guerra (2003), la institución escolar se ve tensionada a nivel de la convivencia y la resolución de conflictos, en la doble tarea de afrontar las diferencias que se manifiestan y también de «transmitir y construir desde valores democráticos y el reconocimiento de la igualdad de todos los seres humanos, por los cuales nadie puede discriminar, rechazar o despreciar nadie» (p. 68). 
En resumen, la escuela chilena gestiona predominantemente la diversidad cultural desde una perspectiva asimilacionista, donde es vista como un problema, un obstáculo; ya sea para el alumno o alumna foránea (quienes se ven obligados a superar sus deficiencias) como para el alumnado autóctono (que ve amenazado su nivel académico). Por tanto, el rol de la escuela será borrar las diferencias mediante una educación igual para todos. Este modelo también convive con una perspectiva multiculturalista, que asume la diversidad cultural reconociéndola y valorándola, favoreciendo su coexistencia. En este contexto, los escolares migrantes experimentan una doble exclusión: al escolarizarse en establecimientos precarios tanto en aspectos académicos como de infraestructura y al enfrentarse a interacciones complejas que afectan sus identidades, «incidiendo (y limitando) de esta manera en sus posibilidades de desarrollo» (Stefoni et al., 2010, p. 104).

\section{Migrantes y docentes en su condición de oprimidos}

\section{«Extraños llamando a la puerta ${ }^{2} »:$ los escolares migrantes}

Los niños, niñas y jóvenes migrantes, predominantemente latinoamericanos, llaman a la puerta de la escuela chilena, la cual se les abre en razón a derechos establecidos; no obstante, aquello no aminora su condición de extraños, lo que queda como un estigma que la escuela intenta borrar, fiel a su función normalizadora. La extrañeza aumenta cuando las lenguas son diferentes y los colores de la piel se alejan de la blancura, exageradamente valorada por los chilenos, quienes manifiestan una visión negativa de los indios y negros, actitud que para Larraín (2001) es constituyente de la identidad chilena.

A pesar de la vetusta Ley de Extranjería, la puerta de la escuela se abre a los niños, niñas y jóvenes migrantes gracias al derecho resguardado por el marco legal regulatorio de la educación, expresado en la Ley General de Educación (Ministerio de Educación Nacional, 2010). Esta asegura el ingreso al sistema escolar, pero no las condiciones de permanencia y acceso a beneficios, evidenciándose la ausencia de instrumentos que permitan de manera clara asegurar que la vivencia escolar de niños, niñas y adolescentes de origen migrante sea positiva, y donde la escuela no asuma a la diversidad cultural como un problema. No obstante, y bajo el peso de su función reproductora y de homogenización, la institucionalidad escolar no considera la diversidad cultural en aspectos claves como la «formación de identidad o reconocimiento de saberes al interior de los procesos educativos, ya sea en forma de estrategias o normativas que regulan la educación» (Jorquera-

\footnotetext{
${ }^{2}$ Tomamos prestado el título del último ensayo de Zygmunt Bauman (2016).
} 
Martínez, 2017, p. 16); además, está ausente de la Ley General de la Educación (2009) o de la política de convivencia escolar, instrumentos donde se extrañan principios como interculturalidad, diversidad y no discriminación (Jorquera-Martínez, 2017, p. 14). Al respecto, es posible documentar que en la Política nacional de desarrollo curricular (Ministerio de Educación Nacional, 2016a), se realiza un reconocimiento de la realidad pluricultural, plural y diversa en distintos sentidos de la sociedad chilena, conforme al momento actual de reforma educacional, en el cual se observa una preocupación por generar un ordenamiento, una estabilidad curricular. Cada gobierno de turno ha instaurado cambios que toman más años de los que dura un mandato, lo cual ha provocado un desfase en la implementación y apropiación de las nuevas bases curriculares (Mora-Olate, 2018).

Los recién llegados se encuentran con otros cerrojos derivados de factores económicos y sociales, los cuales se concretizan en experiencias de discriminación y segregación, que terminan por dificultar su integración. A respecto, las conclusiones del estudio de Stefoni et al. (2010) son elocuentes al señalar que, si bien la integración de los escolares migrantes no resulta problemática a nivel estructural (derecho garantizado a la educación en su acceso) y cognitivo-cultural (ausencia de barrera idiomática en la mayoría de los casos, que facilita su acceso al currículo escolar), sí es una situación compleja para ellos en el nivel social e identitario; es decir, en términos de la interacción con los pares chilenos y migrantes. Esta relación, especialmente en los sectores más desfavorecidos, no está exenta de violencia, traducida en «golpes, molestias, exclusión de los grupos, la ausencia de sanción para los agresores y la falta de protección para los menores migrantes» (Stefoni et al., 2010, p. 100).

La construcción identitaria resulta afectaba a través de los estereotipos negativos que transportan prejuicios racistas, los cuales sin duda no colaboran con la estabilidad emocional de los niños y jóvenes migrantes, necesaria para el desarrollo de todo proceso educativo. Por lo tanto, la raza, idea asumida por los conquistadores como clave de dominación que ubicaba a los unos en situación natural de inferioridad respecto de los otros (Quijano, 200o), en el Chile del tercer milenio son los conquistados quienes reproducen dicha relación de dominación con los migrantes transnacionales del sur. Es así como los estudios de Tijoux (2013) y de Riedemann y Stefoni (2015) revelan la experiencia de racismo que los estudiantes migrados han vivido en las escuelas chilenas y «la forma en que discursos y prácticas construidas en torno a la nación y lo nacional producen y re-producen fronteras dentro del espacio escolar» (Stang et al., 2020, p. 314). 
Un estado del arte entre los años 2006 y 2017 sobre la inserción de niños y niñas migrantes en el sistema escolar chileno revela «dificultades para avanzar en una inclusión real de la población migrante, así como en un modelo de escuela intercultural que sea capaz de transformar la posición de privilegio de la que goza la cultura dominante y terminar con la inferiorización de la cultura y de los grupos de inmigrantes» (Stefoni \& Corvalán, 2020, p. 2010).

Además, las diferencias curriculares entre el sistema educacional chileno y los países de origen del alumnado extranjero constituyen una barrera en su proceso educativo, en cuanto a su rendimiento y proceso de aprendizaje (Carmona \& Naudón, 2018). Por eso, y a pesar de la visión positiva de la integración considerando el factor cognitivo-cultural referido por Stefoni et al. (2010), estimamos que es necesario profundizar la mirada en la cuestión de los saberes que transporta el currículo escolar eurocentrado. Siguiendo a Lander (2000), la construcción eurocéntrica «piensa y organiza a la totalidad del tiempo y del espacio, a toda la humanidad, a partir de su propia experiencia, colocando su especificidad histórico-cultural como patrón de referencia superior y universal» (p. 23). En consecuencia, la ventaja de compartir una misma lengua - que permitiría un aprendizaje más fluido del currículo nacional - invisibiliza una relación de dominación del saber, porque la historia y los saberes tradicionales de los escolares foráneos son integrados en clave de folclorización y no permean la matriz curricular, así como tampoco tensionan categorías como de identidad nacional o el rol de la escuela en su construcción, considerando los escenarios crecientes de diversidad cultural migrante que ella enfrenta.

\section{Los docentes opresores/oprimidos: un rol conflictivo}

El profesorado ha recibido una formación homogénea y, a su vez, el sistema escolar le proporciona una serie de instrumentos de control (currículo prescrito, textos de estudio) para reproducir dicha homogenización en sus acciones pedagógicas rutinizadas, que legitiman y crean las condiciones para que los y las docentes desconozcan la violencia simbólica que ejercen. Al respecto, Althusser (1987) señala que los profesores y las profesoras no tienen conciencia del «trabajo que el sistema (que los rebasa y aplasta) les obliga a realizar» (p. 46). Aquí se revela su condición de opresor/oprimido, añadiéndome a este último aspecto el factor de la política curricular, que consuetudinariamente ha relegado al docente al rol de un mero ejecutor de ideas pensadas por otros. Siguiendo con Althusser (1987), un rol como agente de la represión, pero sin conciencia de su rol de explotado: «están tan lejos de imaginárselo que contribuyen con su devoción a mantener y alimentar 
esta representación ideológica de la escuela, que la hace tan natural e indispensable, y hasta bienhechora, a los ojos de nuestros contemporáneos» (p. 45).

Esta doble arbitrariedad de la acción pedagógica (Bourdieu \& Passeron, 1996) desarrollada por los docentes como violencia simbólica, ejerce un rol opresor que reproduce los objetivos de la clase dominante y la arbitrariedad que permite que esta lo siga siendo; así, se contribuye de forma directa a la naturalización de la cultura arbitrariamente inculcada otorgándole legitimidad, a través de su presencia en el currículo escolar.

Si comenzamos a sacar el velo a la discursividad profesionalizante en la cual está inserta la situación del profesorado, emerge su condición de oprimido y de migrante en la escuela, para lo cual esgrimimos argumentos desde cuatro vertientes: la formación inicial docente, la política educativa, el currículo y las pruebas de medición.

Cabe señalar que Chile contaba con una tradición en la formación pedagógica que data de 1842 con la fundación de la Escuela Normal de Preceptoras en Santiago de Chile y que avanza en 1889 con la creación del Instituto Pedagógico de la Universidad de Chile (Núñez, 2002), donde se formaron profesores secundarios. Ambos hitos resultaron modélicos para toda Latinoamérica. Esta tradición se interrumpe abruptamente con el Golpe Militar en el 1973, el cual trajo como consecuencia el cierre de las escuelas normales, con un «afán de intervenir ideológicamente la educación y motivados por factores económicos» (Castro, 2015, p. 13), siendo sus estudiantes traspasados a las universidades. Iniciada la década de los ochenta, las carreras de pedagogías se decretan como no universitarias, dictándose bajo el alero de Academias Superiores o Institutos Profesionales (Castro, 2015).

El regreso a la democracia en 1990, y específicamente desde 1996, se inicia un ambicioso proceso de reforma educacional, con el que el profesorado perseguía un fortalecimiento de la profesión docente, en términos de un mejoramiento de las condiciones de trabajo y remuneración, así como una renovación de la formación inicial (ContrerasSanzana \& Villalobos-Clavería, 2010) que, al igual que el sistema escolar, responde a un paradigma curricular por competencias. Este ha sido implementado por muchos países del cono sur y deriva del Proyecto Tuning de origen europeo, cuya síntesis formativa para el profesorado se centra en los respectivos estándares pedagógicos y disciplinarios para la formación docente (Ministerio de Educación Nacional, 2011; Ministerio de Educación Nacional, 2012 a; Ministerio de Educación Nacional, 2012 b). Por consiguiente, la mirada reformista se ampara en modelos foráneos de construcción del conocimiento, invisibilizando a los actores en su contexto, en este caso el profesorado, quienes han sido formados 
para implementar las políticas educativas, pero no para participar en su diseño o reflexionar en torno a su pertinencia.

El resultado de esta visión homogeneizadora de la formación inicial del docente, promovida por el Estado a través de los programas Mecesup implementados por las facultades de educación, forman a un profesor o profesora que adolece de competencias profesionales que le permitan participar en la política pública (ya sea en su diseño o transposición didáctica reflexiva y contextualizada en el aula), asumiendo entonces solo un rol técnico de implementación sin cuestionar lo que otros han pensado por ellos. Es así como la formación «mantiene una lógica cultural asimilacionista que se ocupa de entregar habilidades blandas para manejar lo inmediatamente evidente de los conflictos producidos por el choque cultural entre migrantes y autóctonas a fin de mantener el orden» (Carmona \& Naudón, 2018. p. 19), en lugar de fomentar en la formación del docente, la valoración de la diversidad cultural de la sala de clases y la entrega de herramientas que le permitan cuestionar la pertinencia de aspectos como el curricular).

De tal manera, el rol de explotado permanece subsumido en el discurso ministerial profesionalizante, derivado del paradigma por competencias que subyace en la formación inicial, expresado en los estándares, en la evaluación de desempeño y en la reciente política nacional docente, amparada en la Ley 20903 (Ministerio de Educación, 2016b), que crea el Sistema de Desarrollo Profesional Docente.

En el diseño de la política educativa el poder de incidencia de los docentes de aula escasea, a pesar de las ejecuciones dramatúrgicas que se desplegaron en 2015 como los diálogos para la profesión docente, que más allá de generar plataformas de propuestas y de discusión ciudadana para el proyecto de Ley 20903 sobre profesión docente, se desvanecen en el nivel central.

Situación similar se observa en el diseño del currículo nacional, que resulta descontextualizado frente a la diversidad cultural, geográfica, étnica y lingüística de Chile, siendo un currículo pensado por especialistas de cada área, en ausencia de los verdaderos expertos que son los profesores que viven el día a día del aula, mayoritariamente en contextos de vulnerabilidad; entonces, dichos docentes son reducidos únicamente a la ejecución de los planes y programas. El encasillamiento se hace aún más patente en los docentes que tienen a cargo cursos que rinden la prueba Simce (que busca medir la calidad de la educación), para quienes resulta bastante complejo salirse del enmarcamiento que dicha prueba de medición los somete. Por tanto, los establecimientos tienden a tomar medidas cómo adiestrar a los alumnos y alumnas en el arte de responder una prueba de selección de 
múltiple y de lograr la cobertura curricular que el programa de estudio prescribe, dejando un nulo espacio para que el propio docente tome las decisiones pedagógicas acordes al ritmo de aprendizaje de sus estudiantes y a las condiciones socioculturales que lo rodean.

Por ello, al igual que los estudiantes migrantes, el profesorado sufre una asimilación cultural, porque están constreñidos a una implementación acrítica de la política educativa según los énfasis de los gobiernos de turno. En ella el saber pedagógico es despreciado al igual que su categoría de intelectuales, la cual no es relevada por la carrera docente, que más bien profundiza el individualismo en lugar de valorizar el trabajo mancomunado del profesorado para la mejora educativa.

Los cuatro argumentos planteados — que fundamentan la opresión que enfrenta el profesorado- condicionan a los docentes en sus prácticas pedagógicas en aulas diversas culturalmente por la presencia de estudiantes migrados. La evidencia empírica revela las tensiones curriculares que ocasiona la presencia de alumnado migrante y cómo la escuela reacciona con medidas de adaptación (Hernández, 2016); por su parte, Jiménez et al. (2018) subrayan los silencios del currículo en cuanto a su representatividad cultural. Poblete (2018) apunta a los esfuerzos del profesorado y de las escuelas por visibilizar la cultura de los escolares extranjeros, enfrentándose a la percepción de los docentes de una la ausencia de preparación para realizar adaptaciones y de una poca flexibilidad curricular (Castillo et al., 2019). Lo anterior se desarrolla teniendo como telón de fondo para el profesorado chileno un proceso de desplazamiento de la función intelectual a un rol técnico desde la reforma educacional impulsada en el gobierno de Eduardo Frei Montalva en la década de los sesenta (Oliva, 2008, 2017) y que ha sido profundizado en las reformas sucesivas, tanto de la dictadura como en los gobiernos democráticos posteriores.

\section{Posibilidades para una conclusión liberadora}

En la escuela chilena prevalecen trazas de la perspectiva etnocentrista, es decir, eurocéntrica y relativista en relación a cómo la diversidad cultural se encuentra presente/ausente en el currículo. Avanzar hacia una superación esperanzadora de la opresión que experimentan escolares migrantes y docentes - y que ha sido el foco de estas reflexiones-implica dar pasos hacia una concepción dialógica, de igualdad de diferencias. En términos de Freire (2008), ello alude a una pedagogía liberadora que ejerce un liderazgo revolucionario, estableciendo con los oprimidos una relación permanentemente dialógica, donde educadores y educandos, en relación con la realidad, «se encuentran en una tarea en que 
ambos son sujetos en el acto, no solo de descubrirla y así reconocerla críticamente, sino también en el acto de recrear este conocimiento» (p. 68).

Se estima que, para la asunción de un paradigma dialógico en la escuela, se depende principalmente de la toma de conciencia del docente de su condición de oprimido (Freire, 20o8), la cual comparte con aquellos niños, niñas y jóvenes de otras latitudes que arriban a su sala de clases. Una migrancia compartida en términos del estatus que adquieren en el espacio de la escuela los saberes que ambos actores portan, los cuales han sido subyugados a un modelo homogéneo en defensa de una supuesta igualdad.

Para lograr aquel diálogo verdadero, cobra sentido la idea del equilibrio epistemológico propuesta por Fornet-Betancourt (2006) como condición sine qua non, en donde la diversidad cultural pueda encarnarse en los procesos cognitivos y de innovación que deciden en el fondo sobre la manera en que se hace realidad y se planea la configuración futura en el mundo. Lo anterior, dado que la violencia epistemológica de la actualidad es una «situación de desequilibrio que pone en peligro de desaparición la diversidad cultural e incluso la vida en la tierra» (Fornet-Betancourt, 2006, p. 51), siendo la reacción atingente el diálogo intercultural como diálogo abierto entre saberes y tecnologías. La apuesta de la interculturalidad (ya sea para la formación inicial docente como para la idea de escuela) es una apuesta por la diversidad cultural, subrayando que se trata de una diversidad cultural en diálogo; y en este diálogo intercultural juega un papel de primer orden el diálogo de conocimientos y saberes, porque estos son el corazón de la diversidad cultural y los que realmente configuran el perfil de sus diferencias.

La pedagogía crítica provoca un giro en el rol del docente, desde el actual paradigma profesionalizante hacia un giro de la profesionalidad, con un énfasis en el mejoramiento del prestigio y reconocimiento de la posición y función social como un intelectual, lo cual interpela también a la formación inicial para iniciar un proceso de liberación. La transformación requerida debe buscar formar «maestros con identidad, capacitados para inducir relaciones interculturales adecuadas y de proponer cambios y asumir innovaciones pedagógicas que resulten útiles para la vida» (Moya, 2007, p. 250). Entonces, la escuela históricamente diversa exige la formación de un docente crítico, que se asume como un actor social que construye y reconstruye política educativa desde su quehacer de aula; además, como un agente comunitario en contextos de diversidad cultural y de vulnerabilidad y que reconoce e integra en su currículo los saberes de la comunidad de la que forma parte. Cabe recordar que la formación inicial docente en Chile no incluye las diversidades que el profesorado enfrentará en su desempeño profesional, sean estas geográficas, 
étnicas, culturales, lingüísticas y sociales. Al respecto, y en sintonía con la pedagogía crítica, una forma de salida a dicha falencia estaría en lo que Ferrada (2019) aplica para los contextos de pobreza: «reconocer el saber acumulado en la experiencia del profesorado» (p. 12). En el caso que nos ocupa, implica revalorizar la experiencia que vienen teniendo -ya por una década- los profesores y profesoras chilenos que escolarizan estudiantes migrados. Por lo tanto, es hora que las facultades de educación profundicen el vínculo con el profesorado en ejercicio en aulas con diversidad cultural migrante y legitimen su saber como parte de la trayectoria formativa del estudiante de pedagogía.

La esperanza liberadora se resume en una pedagogía crítica, capaz de pensar en una escuela que acoge a las personas con sus proyectos migratorios, donde el currículo escolar es tensionado, en términos de Giroux (2003), desde un multiculturalismo insurgente; este, llevado al terreno pedagógico, debería permitir que tanto docentes como estudiantes puedan «entender cómo funciona el poder en beneficio de las relaciones dominantes y cómo pueden estas impugnarse y transformarse» (p. 344). Desde esta mirada multicultural insurgente la escuela estaría llamada a «expandir las posibilidades de que diferentes grupos entablen un diálogo para entender más profundamente la riqueza de sus diferencias y el valor de lo que tienen en común» (Giroux, 2003, p. 350); donde categorías que creíamos establecidas desde la escuela como aparato ideológico (como la de identidad nacional) resulten tensionadas, y más bien nos conduzcan a replantearlas desde los escenarios crecientes de diversidad cultural.

Reconocemos a América Latina como un lugar de producción de pensamiento emancipador, que nutre el tipo de educación necesaria de construir en contextos crecientes de diversidad cultural migrante y que cuestionan las formas de pensamiento colonizadas que sustentan (tanto los actuales procesos de formativos de los escolares y de los docentes) desde una perspectiva monocultural del currículo escolar.

Por lo tanto, la esperanza liberadora está puesta en una pedagogía crítica con fundamentos en la filosofía intercultural latinoamericana. La interculturalidad entiende que el equilibrio epistemológico supone la recuperación y reinvindicación de los muchos conocimientos contextuales justo en lo que saben por ser o por provenir de tal lugar. «Esa sabiduría lugareña es la que pluraliza los conocimientos y es, por tanto, la que hay que aprender a compartir para generar universalidad en un mundo equilibrado» (Fornet-Betancourt, 2006, p. 53). El carácter crítico de la pedagogía latinoamericana invita a replantear el rol del docente entrampado en su doble arbitrariedad y como parte del mecanismo ideológico de la escuela, liberándolo a través de una profesionalidad que entiende la autoridad 
(siguiendo a Pinto, 2014) como sabiduría. Allí el rol del educador es ser un conversador persuasivo, que establece una relación matricial con el estudiante, basada comunicativamente en la persuasión, el diálogo, el saber el escuchar y el conversar, lo cual permite establecer «relaciones más complementarias entre autoridad, sabiduría y educandos populares; entre decisiones de conducción y participación diferenciada» (Pinto, 2014, p. 64).

Es decir, el pedagogo crítico ya no sería un oprimido, un migrante en su propia escuela, ya que a través sus acciones pedagógicas se libera del autoritarismo, en el ejercicio de una autoridad con rasgos chamánicos, heredera de la tradición indígena, basada en la complementariedad y colaboración. Desde aquella sus acciones están basadas en el respeto por el otro y en diálogo con los educandos. En esta línea, de acuerdo a los hallazgos de Mora-Olate (2020), «a pesar de las carencias formativas en educación intercultural, son los docentes, y no la política pública, quienes estarían abriendo ciertos caminos en la línea de la pedagogía intercultural, a través de la legitimación del saber migrante» (p. 142).

Los escolares migrantes también saldrían de su condición de oprimidos al escucharse sus voces y saberes en el cruce epistemológico del saber oficial con el saber emergente de la pedagogía crítica; esta, a juicio de Pinto (2014), tiene dos objetivos: «aumenta la autoestima y la confianza del educando en su capacidad de mostrar que sabe, y por otro lado, posiciona la curiosidad de aprender del educando en una perspectiva de interés epistemológico frente a cualquier tema o problema que les preocupa» (p. 40).

En resumen, las escuelas y los docentes pueden convertirse en instituciones al servicio de las necesidades de los niños y niñas migrantes e hijos e hijas de inmigrantes en Chile a través de la construcción de una pedagogía crítica; en su ejercicio, tanto estudiantes como docentes, en relación dialógica, lograrían una conciencia de la opresión a través de una praxis que es reflexión y acción de los seres humanos sobre el mundo para transformarlo (Freire, 2008), haciendo posible contradecir la idea de realidad opresora, no como un mundo cerrado, sino transformable. En ello deposito mi esperanza liberadora.

\section{Referencias}

Albert, M. J. (2007). La investigación educativa: claves teóricas. McGraw-Hill. Althusser, L. (1987). Ideología y aparatos ideológicos del estado. Ediciones del Quinto Sol. Bourdieu, P. (2003). Capital cultural, escuela y espacio social. Siglo XXI Editores. 
Bourdieu, P. \& Passeron, J. (1996). La reproducción: elementos para una teoría del sistema de enseñanza. Distribuciones Fontamara.

Carmona, K., \& Naudón, P. (2018). Percepción docente sobre alumnado migrante, acciones, estrategias y apoyos: aproximaciones desde un estudio cuantitativo on-line. Revista Academia y Crítica, (2), 1-24.

Castillo, D., Santa-Cruz, E., \& Thayer, E. (2019). Estudiantes migrantes en escuelas públicas chilenas. Programa Interdisciplinario de Investigaciones en Educación; Editorial Aún Creemos en los Sueños.

Castro, F. (2015). Formación de profesores en Chile: una mirada crítica ante la encrucijada histórica de los cambios educacionales. Praxis Educativa, 19(1), 12-19.

Contreras-Sanzana, G., \& Villalobos-Clavería, A. (2010). La formación de profesores en Chile: una mirada a la profesionalización docente. Educación y Educadores, 13(3), 397-417. https://doi.org/10.5294/edu.2010.13·3.5

Eyzaguirre, S., Aguirre, J., \& Blanco, N. (2019). Dónde estudian, cómo les va y qué impacto tienen los escolares inmigrantes. En I. Aninat, \& R. Vergara (Eds.), Inmigración en Chile: una mirada multidimensional (pp. 149-189). Fondo de Cultura Económica; Centro de Estudios Públicos.

Ferrada, D. (2019). La sintonización en la formación inicial docente: una mirada desde Chile. Revista Electrónica de Investigación Educativa, 21, e39, 1-14. https://doi.org/gb4p

Fornet-Betancourt, R. (2006). La interculturalidad a prueba. Mainz.

Freire, P. (2008). Pedagogía del oprimido. Siglo XXI.

Fuentes, A., \& Hernando, A. (2019). Caracterización estadística de la inmigración en Chile. En I. Aninat, \& R. Vergara (Eds.), Inmigración en Chile: una mirada multidimensional (pp. 379-407). Fondo de Cultura Económica; Centro de Estudios Públicos.

Giroux, H. (2003). Pedagogía y política de la esperanza. Amorrortu.

Henao-Agudelo, C., Lalueza, J. L., \& Tenorio, M. C. (2016). Valores y prácticas educativas de familias latinoamericanas inmigradas en Barcelona: ¿qué cambia y qué permanece? Revista Latinoamericana de Ciencias Sociales, Niñez y Juventud, 14(1), 603-615.

Hernández, A. (2016). El currículo en contextos de estudiantes migrantes: las complejidades del desarrollo curricular desde la perspectiva de los docentes de aula. Estudios Pedagógicos, 42(2), 151-169. https://doi.org/10.4067/s0718-07052016000200009

Jiménez, F. (2012). Violencia escolar en contextos educativos multiculturales: una aproximación desde los modelos de gestión de la diversidad cultural. Psicoperspectivas. Individuo y Sociedad, 11(2), 8-30. https://doi.org/gb4r 
Jiménez, F., Valdés, R., \& Aguilera, M. (2018). Geografías de la investigación académica sobre migración y escuela: voces, silencios y prospectivas de nuestra profesión. Estudios Pedagógicos, 44(3), 173-191. https://doi.org/10.4067/s0718-07052018000300173

Jorquera-Martínez, C. (2017). Políticas públicas y derecho a la educación de niños, niñas y adolescentes extranjeros en Chile. Revista Electrónica Actualidades Investigativas en Educación, 17(1), 1-19. https://doi.org/10.15517/aie.v17i1.27297

Lander, E. (2000). Ciencias sociales: saberes coloniales y eurocéntricos. En E. Lander (comp.), La colonialidad del saber: eurocentrismo y ciencias sociales. Perspectivas Latinoamericanas (pp. 11-40). Clacso.

Larraín, J. (2001). Identidad chilena. LOM.

Martín-Criado, E. (2010). La escuela sin funciones: crítica de la sociología de la educación crítica. Bellaterra.

Ministerio de Educación [Chile]. (2010). Ley General de Educación (Ley 20 370, 17 de agosto del 2009). http://www.leychile.cl/Navegar?idNorma=1014974

Ministerio de Educación [Chile]. (2011). Estándares orientadores para egresados de carreras de Pedagogía en educación básica. https://bit.ly/34D27BF

Ministerio de Educación [Chile]. (2012a). Estándares orientadores para egresados de carreras de Pedagogía en educación parvularia. https://bit.ly/2RV28yg

Ministerio de Educación [Chile]. (2012b). Estándares orientadores para egresados de carreras de Pedagogía en educación media. https://bit.ly/2Re8Bnx

Ministerio de Educación [Chile]. (2016a). Recomendaciones para una política nacional de desarrollo curricular. Informe Mesa de Desarrollo Curricular. Unidad de Currículum y Evaluación.

Ministerio de Educación [Chile]. (2016b). Ley Sistema de Desarrollo Profesional Docente (Ley 20 903). https://bit.ly/3uG42Rp

Ministerio de Educación [Chile]. (2018). Mapa del estudiantado extranjero en el sistema escolar chileno (2015-2017). https://bit.ly/3bkKytL

Mora-Olate, M. L. (2018). Política educativa para migrantes en Chile: un silencio elocuente. Polis (Santiago), 17(49), 231-257. https://doi.org/10.4067/s0718-65682018000100231

Mora-Olate, M. L. (2020). Currículum y diversidad cultural: un estudio desde disciplinas escolares y discursos docentes en establecimientos educacionales con alumnado de origen migrante [Tesis doctoral no publicada]. Universidad del Bío-Bío.

Moya, R. (2007). Formación de maestros e interculturalidad. En R. Cuenca, N. Nucinkis, \& V. Zavala (Comps.), Nuevos maestros para América Latina (pp. 229-258). Morata. 
Núñez, I. (2002). La formación de docentes: notas históricas. En B. Ávalos (Ed.), Profesores para Chile: historia de un proyecto (pp. 14-39). Ministerio de Educación.

Oliva, M. A. (2008). Política educativa y profundización de la desigualdad en Chile. Estudios Pedagógicos, 34(2), 207-226. https://doi.org/10.4067/s0718-07052008000200013

Oliva. M. A. (2017). Arquitectura de la política educativa chilena (1990-2014): el currículum, lugar de la metáfora. Revista Brasileira de Educação, 22(69), 405-428. https:// doi.org/10.1590/s1413-24782017226921

Orellana, M. (2009). Cultura, ciudadanía y sistema educativo: cuando la escuela adoctrina. LOM.

Pinto, R. (2014). Pedagogía crítica para una educación pública y transformadora en América Latina. Derrama Magisterial.

Poblete, R. (2018). El trabajo con la diversidad desde el currículo en escuelas con presencia de niños y niñas migrantes: estudio de casos en escuelas de Santiago de Chile. Perfiles Educativos, 40(159), 51-65. https://doi.org/10.22201/iisue.24486167e.2018.159.58202

Quijano, A. (2000). Colonialidad del poder, eurocentrismo y América Latina. En E. Lander (Comp.), La colonialidad del saber: eurocentrismo y ciencias sociales. Perspectivas Latinoamericanas (pp. 201-246). Clacso.

Quintriqueo, S., Quilaqueo, D., Lepe-Carrión, P., Riquelme, E., Gutiérrez, M., \& PeñaCortés, F. (2014). Formación del profesorado en educación intercultural en América Latina: el caso de Chile. Revista Electrónica Interuniversitaria de Formación del Profesorado, 17 (2), 201-217. https://doi.org/10.6018/reifop.17.2.198021

Riedemann, A., \& Stefoni, C. (2015). Sobre el racismo, su negación, y las consecuencias para una educación anti-racista en la enseñanza secundaria chilena. Polis, Revista Latinoamericana, 14(42), 191-216. https://doi.org/10.4067/s0718-65682015000300010

Sabariego, M., Massot, I., \& Dorio, I. (2012). Métodos de investigación cualitativa. En A. Bisquerra (Coord.), Metodología de la investigación educativa (pp. 293-328). La Muralla. Santos-Guerra, M. (2003). Aprender a convivir en la escuela. Universidad de Andalucía; Akal. Segovia, P., \& Rendón, B. (2020). Estudiantes extranjeros/as en la representación de los docentes en una escuela de Santiago: elementos para una educación intercultural. Polis (Santiago), 19(56), 240-266. https://doi.org/10.32735/so718-6568/2020-n56-1528

Serrano, S., Ponce de León, M., \& Rengifo, F. (2013). Historia de la educación en Chile (1810-2010): Tomo 1. Aprender a leer y escribir (1810-1880). Taurus.

Stefoni, C., Acosta, E., Gaymer, M., \& Casas-Cordero, F. (2010). El derecho a la educación de los niños y niñas inmigrantes en Chile. Universidad de Deusto.

Stefoni, C., \& Corvalán, J. (2020). Estado del arte sobre inserción de niños y niñas migrantes en el sistema escolar chileno. Estudios Pedagógicos, 45(3), 201-215. https://doi.org/f7c7 
Stang, M., Roessler, P., \& Riedemann, A. (2020). Re-producción de fronteras en el espacio escolar: discursos y prácticas de distinción nacional(ista) en escuelas con alumnado migrante en la Región Metropolitana de Chile. Estudios Pedagógicos, 45(3), 313-331. https://doi.org/10.4067/s0718-07052019000300313

Tijoux, M. E. (2013). Las escuelas de la inmigración en la ciudad de Santiago: elementos para un educación contra el racismo, Polis. Revista Latinoamericana, 12(35), 287-307. https://doi.org/10.4067/s0718-65682013000200013 